\section{Pre-Clinical Study Of Safeness Of The Drug}

\section{Ferulen}

Tukhtasheva Visola Farmonovna,

Phd Student, Junior Researcher, Department Of Pharmacology And

Toxicology, S.Yu. Yunusov Institute Of The Chemistry Of Plant

Substances, Academy Of Sciences Of The Republic Of Uzbekistan.

\section{Rejepov Jumadulla,}

Candidate Of Medical Sciences, Leading Researcher, Head Of The

Department Of Pharmacology And Toxicology, S.Yu. Yunusov

Institute Of The Chemistry Of Plant Substances, Academy Of

Sciences Of The Republic Of Uzbekistan.

Djakhangirov Farkhod Nabievich,

Doctor Of Medical Sciences, Chief Researcher, Department Of

Pharmacology And Toxicology, S.Yu. Yunusov Institute Of The

Chemistry Of Plant Substances, Academy Of Sciences Of The

Republic Of Uzbekistan.

\section{Azamatov Azizbek Azamat Ugli,}

Junior Researcher, Department Of Pharmacology And Toxicology,

S.Yu. Yunusov Institute Of The Chemistry Of Plant Substances, Academy Of Sciences Of The Republic Of Uzbekistan.

\section{Zakhidova Lola Tishaevna}

Candidate Of Biological Sciences, Senior Researcher, Department Of Pharmacology And Toxicology, S.Yu. Yunusov Institute Of The Chemistry Of Plant Substances, Academy Of Sciences Of The Republic Of Uzbekistan.

\section{G OPEN ACCESS}

The American Journal of Medical Sciences And Pharmaceutical Research

JULY 2020

Page No.: 134-143

Volume-II Issue-VII

PUBLISHED: 31 JULY 2020

www.usajournalshub.com/inde

x.php/TAJMSPR

Copyright: Original content from this work may be used under the terms of the Creative Commons Attribution 4.0 licence. 


\section{Abstract}

The acute toxicity, cumulative effect and chronic toxicity of the drug "Ferulen" were studied. During the experiments on white mice and rats with oral injection, it was found that the drug ferulen by the parameters of acute toxicity belongs to the category of practically non-toxic substances ( $\mathrm{V}$-class). The coefficient of sexual and species sensitivity of the drug is not expressed.

Ferulen is not accumulated in the body of animals when used repeatedly. Long-term use of ferulen for 90 days is well experienced by experimental animals. At the same time, biochemical parameters indicated that there was a deduction in urea, cholesterol, $\beta$ lipoproteins and lipids, as well as decrease in testosterone and luteinizing hormone in the blood serum. In pathomorphological and histological studies a significant decrease in the mass of androgen-dependent organs and destructive changes were found.

Keywords: ferulen, prostate, acute toxicity, cumulation, chronic toxicity, testosterone, luteinizing hormone, androgen-dependent organs

\section{Introduction}

Ferula plant species are native to Central Asia where the maximum variety of species of this plant is found [1-3].

Under the systematic study of chemical compounds of various types ferula plants of Uzbekistan, fellow workers of the institute of chemistry of plant substances academicians $R U z$, for the first time over the globe has identified that various ferula plants consist of not only terpenoid coumarins and sesquiterpenoid lactones, but also consist of a new set of natural compounds - aliphatic and aromatic acids of esters of terpenoid alcohols $[4,5]$. Texture and stereochemical properties of more than 150 new varieties of terpenoids have been established.

In the department of pharmacology and toxicology of the Institute of plant chemistry, the estrogenic activity of various types of ferula was identified for the first time.

As a result of these studies, a new phytoestrogens have been developed and introduced into practical medicine - tefestrol is used in gynecological practices, the drug panoferol is used in poultry and veterinary practices to increase the egg production of chickens and prevent barrenness in sheep and cattle $[6,7]$.

The drug ferula is a natural mixture of esters of sesquiterpene alcohols, the components of which are ferutinin (main), tenuferodin, ferritin, and fertidin that obtained from the root parts of a thin-cut/section ferula (Ferula tonuisecta korov of the celery family-ape cease).

The results of pharmacological studies previously found, showed that ferula has a pronounced estrogenic and antiprostatic effects in the experiment $[8,9]$.

In this regard, the purpose of this research was to study the degree of safeness of ferula in a preclinical toxicological experiment.

\section{Methods of research}

Experiments on animals were conducted following the guidelines adopted by the European Convention for the protection of vertebrates used for experimental and other scientific purposes (European Convection for the Protection of Vertebrate Animals Used for Experimental of her Scientific Purposes (ETS123) Strasburg, 1986). 
The experiments of the parameters of acute toxicity of ferula was carried out on nonlinear white mice weighing $18-20 \mathrm{~g}$ and rats weighing 190-210 g with an oral method of application using an atraumatic metal probe. The average lethal dose was determined based on the Litchfield Wilcoxon method [10].

The study of the possible cumulative effect of ferule was carried out on experimental male white rats. The drug was injected daily 7 times a week to the stomach at a dose of $2000 \mathrm{mg} / \mathrm{kg}$ (1/3 LD 50$)$ for 21 days. Statistical processing of the obtained data was carried out using the Microsoft Excel program in Windows XP and Statistica 6.0 - for the variation series of variables, the arithmetic mean $(M)$ and its error $(m)$ was calculated. The student's t-criteria was used to assess the reliability of differences between the compared values. The variance of the two values was considered reliable at $\mathrm{P}<0.05$.

The experiment of chronic toxicity was carried out on 80 white male rates with an initial weight of $150-170 \mathrm{~g}$. The drug was injected using an atraumatic metal probe daily ( 7 times a week) once a day for 3 months at a dose of $10-50-100 \mathrm{mg} / \mathrm{kg}$. Each dose of the drug was experimented on 20 rats. Control animals received equivale level of distilled water. The level of experimental doses represents that $10 \mathrm{mg} / \mathrm{kg}$ corresponded to the therapeutic antiprostatic activity in the study of specific activity, the maximum dose of $100 \mathrm{mg} / \mathrm{kg}$ represented a 10-fold therapeutic dose. The dose of $50 \mathrm{mg} / \mathrm{kg}$ was intermediate.

During the experiment, a general condition, behaviors, reaction to external irritants, skin conditions, hair, visible mucous membranes, etc. were recorded daily. While body weight was recorded weekly. After 10-30-60 days since the beginning of the experiment, hematological studies of peripheral blood were analyzed on BC-2300 hematological analyzer from Mindray (China).

Biochemical parameters of blood serum were performed on a biochemical analyzer BASIC SECOMAM (France). The content of luteinizing hormone and testosterone in blood plasma was determined. We also registered ECG studies on electrocardiography "ELKAR" produced in Russia, diuresis on the background of $3 \%$ water load, the effects on the central nervous system on the approximate research behavior of animals in an "Open field" conditions. After the end of the chronic toxicity period, 10 animals from each group were euthanized by a $\mathrm{CO} 2$ - chamber. Pieces of internal organs and brain were fixated in $10 \%$ neutral formalin, making histological sections and stained with hematoxylin-eosin.

\section{Results and Discussions}

The results of the research indicate that when ferule was injected orally to white mice and rats of both sexes at doses of $1000-8000 \mathrm{mg} / \mathrm{kg}$, the same pattern of poisoning was revealed at experimental animals, characterized mainly by general oppression, restriction of motional activity, adynamia, and disheveling of the fur coats (starting from a dose of $3000 \mathrm{mg} / \mathrm{kg}$ ) within a day after the drug was injected. Further increase in the dose of the substance caused to the increase of the above-mentioned symptoms and the death of some experimental animals within 1-2 days after the injection of ferule. The absolute fatal dose for mice was $7000 \mathrm{mg} / \mathrm{kg}$, for rats of both sexes $8000 \mathrm{mg} / \mathrm{kg}$. The results of the conducted experiment (table 1 ) showed that ferule belongs to the category of practically non-toxic substances-class IV when injected orally. There were no significant statistical differences in the sensitivity of laboratory animals to the effects of ferule, based on the 
THE AMERICAN JOURNAL OF MEDICAL SCIENCES AND PHARMACEUTICAL RESEARCH

ISSN (e): 2689-1026

DOI: https://doi.org/10.37547/TAJMSPR/Volume02Issue07-18

type and sex of animals.

Table 1

The results of acute toxicity of Ferule

\begin{tabular}{|c|l|c|c|}
\hline $\begin{array}{c}\text { Anima } \\
\text { I kinds }\end{array}$ & Sex & $\begin{array}{c}\text { Method } \\
\text { of injection }\end{array}$ & LD 50 mg/ kg \\
\hline Mice & Male & Gastral & $5600(4869,8 \div 6440)$ \\
Mice & Female & Gastral & $5400(4737 \div 6256)$ \\
Rats & Male & Gastral & $6100(5304,3 \div 7015)$ \\
Rats & Female & Gastral & $5800(5087,7 \div 6612)$ \\
\hline
\end{tabular}

A study evaluating the possible cumulative effect of ferule on male rats showed that daily injection of the drug for 21 days at a dose of $2000 \mathrm{mg} / \mathrm{kg}(1 / 3$ of LD 50$)$ did not cause the death of experimental animals. Meanwhile, experimental animals in the course of the experiment received a total of $42,000 \mathrm{mg} / \mathrm{kg}$ of the drug, which is 7 times higher than the average fatal dose in rats. Accordingly, ferule is not accumulated in the body of experimental animals when re-used for 21 days.

As a result of long-term injection of ferule into the stomach of male rats for 90 days at doses of 10,50 and $100 \mathrm{mg} / \mathrm{kg}$, there was no negative effect on the main integral indicators (gaining body weight, general condition, behavior, feed, and water consumption) and there were no cases of death of rats.

There were no significant statistical differences in the study of hematological parameters of peripheral blood in the dynamics of white blood cells, red blood cells, hemoglobin level, and the picture of the leukocyte formula in all groups of experimental animals with the control group of rats.

Study of biochemical parameters (AIAT, AsAT, glucose, total protein, total cholesterol, urea, lipoproteins, lipids) blood serums of rats (after 90 days) treated with ferule in a chronic experiment showed that ferule reduces the content of urea, $\beta$-lipoproteins, cholesterol, and lipids in comparison with the control group of animals (table 2 ).

Table 2.

Biochemical data of blood serum of rats receiving ferule in a chronic experiment (data after the end of the experiment

\begin{tabular}{|c|c|c|c|c|c|}
\hline & Parameters & $\begin{array}{r}10 \\
\mathrm{mg} / \mathbf{k g}\end{array}$ & $\begin{array}{r}50 \\
\mathrm{mg} / \mathbf{k g} \\
\end{array}$ & $\begin{array}{c}100 \\
\mathrm{mg} / \mathrm{kg}\end{array}$ & Control \\
\hline & AlAt $\mathrm{mmol} /$ & $1,34 \pm 0,1$ & $1,4 \pm 0,12$ & $1,5 \pm 0,19$ & $1,46 \pm 0,0$ \\
\hline $\mathrm{HL}$ & ASAT mmol / & $3,17 \pm 0,1$ & $3,6 \pm 0,18$ & $3,2 \pm 0,16$ & $3,16 \pm 0,0$ \\
\hline / 1 & Glucose $\mathrm{mmol}$ & $5,18 \pm 0,8$ & $5,16 \pm 0,6$ & $5,14 \pm 0,7$ & $5,15 \pm 0,5$ \\
\hline$g / l$ & Total protein & $77,0 \pm 2,4$ & $76,0 \pm 1,9$ & $79,0 \pm 1,7$ & $78,0 \pm 1,8$ \\
\hline & Urea mmol / I & $5,3 \pm 0,63$ & $4,7 \pm 0,61$ & $4,1 \pm 0,54$ & $5,9 \pm 0,61$ \\
\hline
\end{tabular}


THE AMERICAN JOURNAL OF MEDICAL SCIENCES AND PHARMACEUTICAL RESEARCH

ISSN (e): 2689-1026

DOI: https://doi.org/10.37547/TAJMSPR/Volume02Issue07-18

\begin{tabular}{|c|c|c|c|c|}
\hline & & * & $*$ & \\
\hline $\mathrm{g} / \mathrm{l}$-Lipoproteins, & 3* $0,52 \pm 0,0$ & $2 * \quad 0,56 \pm 0,0$ & $2 * \quad 0,55 \pm 0,0$ & $0,67 \pm 0,0$ \\
\hline $\begin{array}{l}\text { Cholesterol } \\
\mathrm{mg} \%\end{array}$ & $62,5 \pm 4,9$ & * $\quad 57,9 \pm 4,1$ & $54,4 \pm 4,6$ & $69,4 \pm 4,6$ \\
\hline Lipids g / I & $3 \quad 1,77 \pm 0,2$ & $1,42 \pm 0,2$ & $1,11 \pm 0,2$ & $2,08 \pm 0,1$ \\
\hline
\end{tabular}

$* \mathrm{P}<0.05$ in comparison with Controls

The results of the study have shown that long-term use of ferulen leads to a decrease in the content of luteinizing hormone and testosterone in the blood serum of experimental rats, depending on the injected dose of ferulen compare to control animals. Therefore, when using a $10 \mathrm{mg} / \mathrm{kg}$ dose of ferule, the content of the luteinizing hormone is reduced by 1.5 times, and testosterone by 1.7 times. Increasing the dose to $50 \mathrm{mg} / \mathrm{kg}$ and 100 $\mathrm{mg} / \mathrm{kg}$ leads to a significant decrease in LG content by 1.8 times, and testosterone by 3.1 times (table 3).

A study on the cardiac conduction system (ECG study) of rats did not reveal the cardiotoxic effect of Ferule in the tested doses during prolonged intragastric use of the drug in experimental animals.

Table 3.

The content of Luteinizing hormone and testosterone in the blood plasma of rats after the end of chronic toxicity (after 90 days)

\begin{tabular}{|c|c|c|c|c|}
\hline $\mathrm{N}$ & Drug name & $\begin{array}{l}\text { Dose } \\
\mathrm{mg} / \mathrm{kg}\end{array}$ & $\begin{array}{r}\text { Luteinizing } \\
\text { Hormone, ME/L }\end{array}$ & $\begin{array}{c}\text { Testoste } \\
\text { rone } \\
\mathrm{Nmol} / \mathrm{l}\end{array}$ \\
\hline 1 & Control & & $34,45 \pm 1,51$ & $5 \quad 9,48 \pm 0,2$ \\
\hline 2 & Ferule & $\begin{array}{l}10 \\
50 \\
100\end{array}$ & $\begin{array}{ll} & 22,36 \pm 1,05 \\
* & 18,77 \pm 0,96 \\
* & 18,36 \pm 1,14 \\
* & \end{array}$ & $\begin{array}{l}5,52 \pm 0,28^{*} \\
3,07 \pm 0,19^{*} \\
3,0 \pm 0,15^{*}\end{array}$ \\
\hline
\end{tabular}

Note. ${ }^{*} \mathrm{P}<0.05$ in comparison with Controls the content of the Luteinizing hormone is expressed in units of activity of the international standard LH 69/104-ME;

Macroscopic examination of the internal organs of rats treated with ferule for 90 days showed a decrease in the mass of the prostate, seminal vesicles, and testes in all tested doses associated with the specific activity of the drug against the target organs. Other organs did not endure significant changes during macroscopic examination (table 4). 
Table 4.

Coefficient of the mass of internal organs of rats receiving ferule in a chronic experiment.

\begin{tabular}{|c|c|c|c|c|}
\hline Organs & $\begin{array}{c}\mathbf{1 0} \\
\mathbf{m g} / \mathbf{k g}\end{array}$ & $\begin{array}{c}\mathbf{5 0} \\
\mathbf{m g} / \mathbf{k g}\end{array}$ & $\begin{array}{c}\mathbf{1 0 0} \\
\mathbf{m g} / \mathbf{k g}\end{array}$ & Control \\
\hline Brain & $6,54 \pm 0,39$ & $6,22 \pm 0,28$ & $6,75 \pm 0,25$ & $6,14 \pm 0,38$ \\
\hline Heart & $3,22 \pm 0,2$ & $3,81 \pm 0,22$ & $3,15 \pm 0,25$ & $3,40 \pm 0,3$ \\
\hline Lungs & $5,52 \pm 0,34$ & $5,42 \pm 0,28$ & $5,9 \pm 0,22$ & $5,66 \pm 0,26$ \\
\hline Liver & $30,9 \pm 1,9$ & $33,2 \pm 2,2$ & $31,6 \pm 1,7$ & $30,4 \pm 2,4$ \\
\hline The Kidneys & $6,8 \pm 0,32$ & $7,1 \pm 0,29$ & $7,42 \pm 0,3$ & $7,7 \pm 0,23$ \\
\hline Spleen & $4,0 \pm 0,45$ & $3,65 \pm 0,4$ & $3,82 \pm 0,4$ & $3,9 \pm 0,31$ \\
\hline Adrenals & $0,17 \pm 0,002$ & $0,15 \pm 0,002$ & $0,16 \pm 0,0018$ & $0,14 \pm 0,0026$ \\
\hline $\begin{array}{c}\text { Ventral } \\
\text { prostate }\end{array}$ & $30 \pm 7^{*}$ & $24 \pm 3^{*}$ & $21 \pm 2^{*}$ & $127 \pm 9$ \\
$\begin{array}{c}\text { Coagulating } \\
\text { gland }\end{array}$ & $19 \pm 2^{*}$ & $15 \pm 2^{*}$ & $11 \pm 1^{*}$ & $55 \pm 3$ \\
\hline $\begin{array}{c}\text { Seminal } \\
\text { vesicles }\end{array}$ & $54 \pm 4 *$ & $44 \pm 4^{*}$ & $32 \pm 8^{*}$ & $96 \pm 6$ \\
\hline $\begin{array}{c}\text { Testes } \\
\text { Testes }\end{array}$ & $805 \pm 40^{*}$ & $722 \pm 32^{*}$ & $680 \pm 28^{*}$ & $1292 \pm 52$ \\
\hline
\end{tabular}

$* \mathrm{P}<0.05$ in comparison with the Controls

Microanatomical examination of the internal organs of experimental animals receiving ferule showed deconstructive changes mainly in androgen-dependent organs (prostate, testes, seminal vesicles).

The prostate gland - lobed structure is observed in the prostate gland of control rats. At the same time, distinctive connective-tissue partitions depart from the organ capsule, dividing it into segments. The final sections of the prostate mucosal glands on the incisions have a variety of shapes and uneven folded contours and are formed by a high prismatic epithelium. There are thick bundles of smooth muscle cells directed longitudinally and circularly around the final sections (Fig. 1).

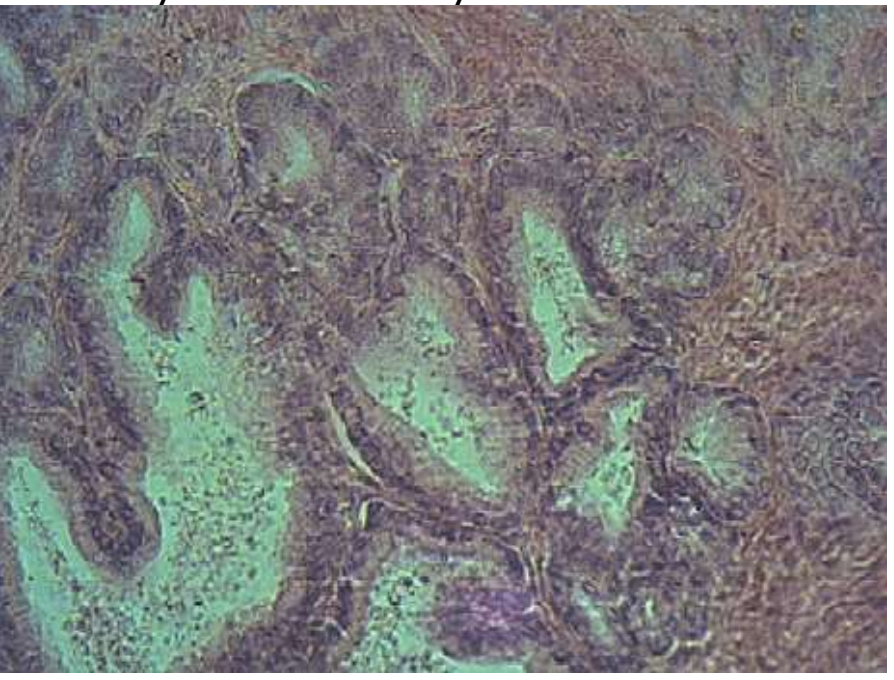


Fig. 1. Prostate gland of control rats. Extension of the final secretory sections. Accumulation and condensation of the sectors in them. Marking with hematoxylin and eosin. Obj. 20, ocular 10.

In experimental rats, after the injection of ferule, the connective tissue partitions of the prostate gland are relatively thin and loosened in the stroma in contrast to relatively few smooth muscle cells, the layers are indistinguishable. The final sections are various in shape, uneven, less folded, and lined with low prismatic or cubic forms. There are destructive and dystrophic changes in the mucosa. Accumulation of internal end-part of the prostate significantly decreased (Fig. 2).

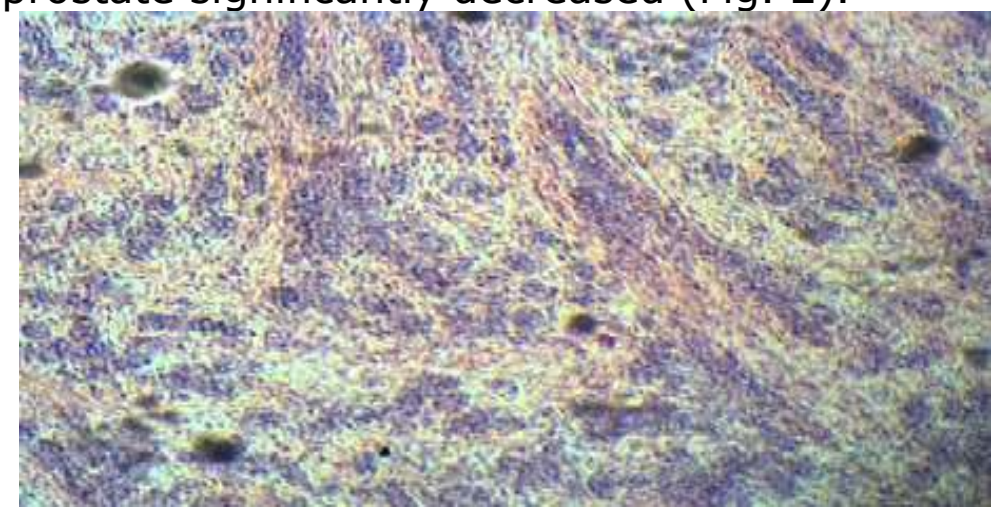

Fig. 2 Reduction and contraction of the end sections of the prostate after administration of ferule. Stained with hematoxylin and eosin. Obj. 8, ocular 10.

Testes - studies of the testes of a control group of rats showed that they are surrounded by a protein shell consisting of connective tissues with quite numerous blood vessels. The parenchyma of an organ is represented by a set of rounded, oval, or prolate sections of elongated seminal tubules, between which the interstitial connective tissue is located. In the latter one usually, groups of several cells of Leydig cells or endocrine gland cells are arranged. The outside part of each seminal canal is surrounded by a connective tissue membrane, to which the basal membrane adjoins. The inner part of the tubules is the socalled spermatogenic epithelium consists of spermatogenesis cells at various stages of differentiation depending on the cycle of spermatogenesis and supporting sustentacular cells located between them. In the lumen of the tubules flocks of mature spermatozoa were found, the number of which was not the same in the tubules located at different levels of the spermatogenic cycle (Fig. 3). 


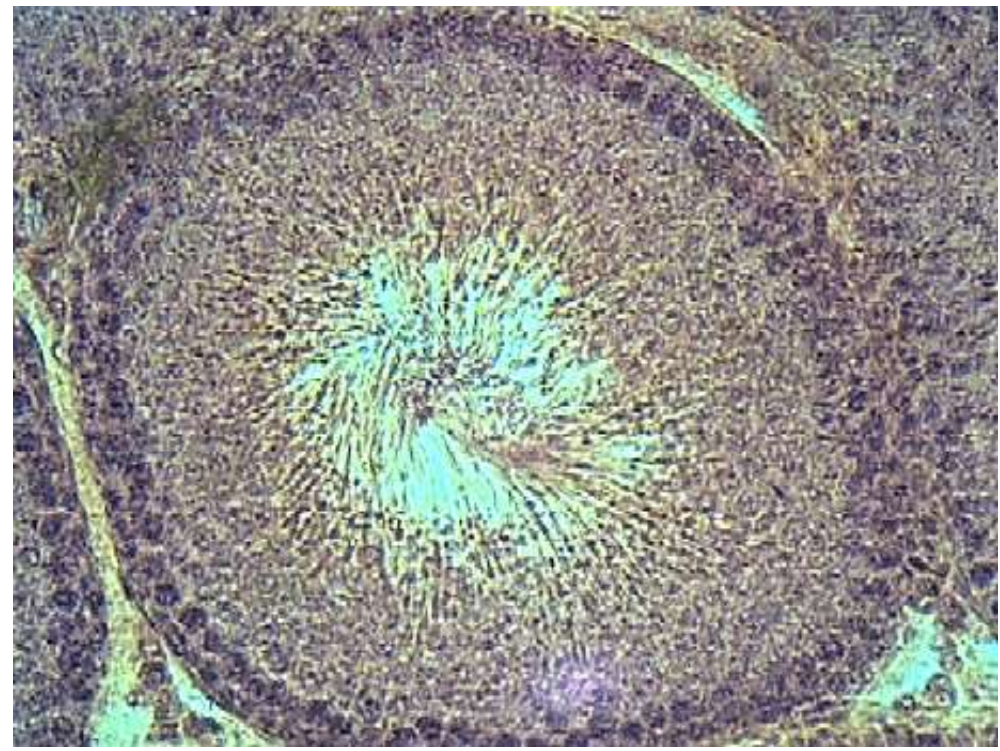

Fig. 3. Testes of control rats. Spermatogenic epithelium consisting of spermatogenesis cells at various stages of differentiation. There are clusters of Mature spermatozoa in the lumen of the tubules. Stained with hematoxylin and eosin. Obj. 20, ocular 10.

Experimental animals showed morphological shifts when ferule was injected compared to the control animals. At the same time, at the background of relatively intact seminal tubules, tubules with destruction and extrusion of spermatogenic cells were identified. There was noted edema, loosening, and fullness of interstitial tissue. The structure of cells of the spermatogenic layer in individual tubules was abnormal - there was a dislocation of spermatocytes and spermatids as a result of intercellular edema. At the background of edema, a decrease in the number of spermatogenic cells called attention in some tubules, mainly spermatocytes and spermatids. The number of spermatozoa in the lumen of the tubules significantly decreased. Meanwhile, in tubules lines, they were completely absent. Along with edema in the interstitial tissue, the presence of destructive or completely destroyed Leydig cells was noted (Fig. 4).

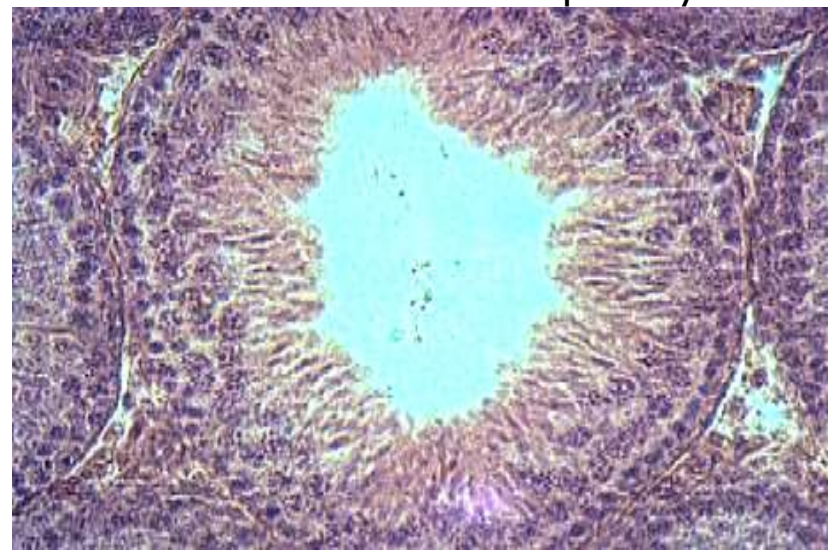

Fig. 4. Testis of rats after injection of ferule. Edema and loosening of interstitial tissue. Decrease in the number of spermatogenic cells in the cell-wall and spermatozoa in the lumen of the tubules. Stained with hematoxylin and eosin. Obj. 20, ocular 10.

Seminal vesicles - in the seminal vesicles of control rats, the mucous membrane is collected in numerous branched folds. The single-layer epithelium has a cylindrical shape. 
In the connective tissue stroma of the mucous membrane, some kinds of alveolar glands are found. The muscle membrane is soundly expressed. The inner and outer layers are marked. The outer shell is formed of dense connective tissues (Fig. 5).

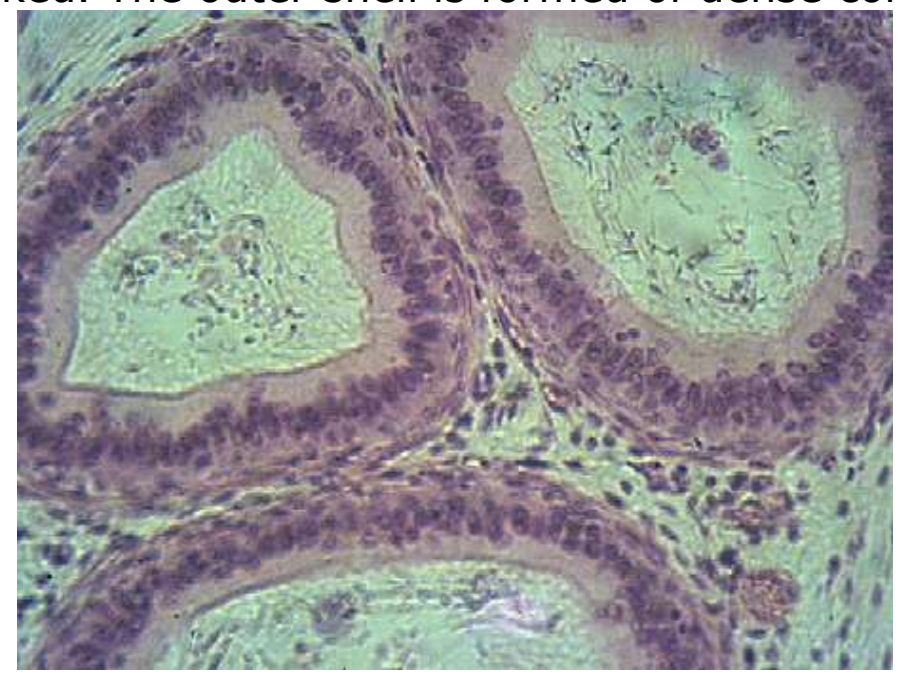

Fig. 5. Seminal vesicles of control rats. The walls are lined with multi-row prismatic epithelium. Stained with hematoxylin and eosin. Obj. 20, ocular 10.

In the experimental groups, the mucosal folds are smoothed with rare branches. Epithelium of low prismatic, sometimes cubic shapes, with signs of destructive-dystrophic changes. The connective tissue layer of the mucosa is thin with few alveolar glands. The muscle membrane is not divided into outer and inner layers. It is notable a decrease in the secretory product and loosening of its mass (Fig. 6).

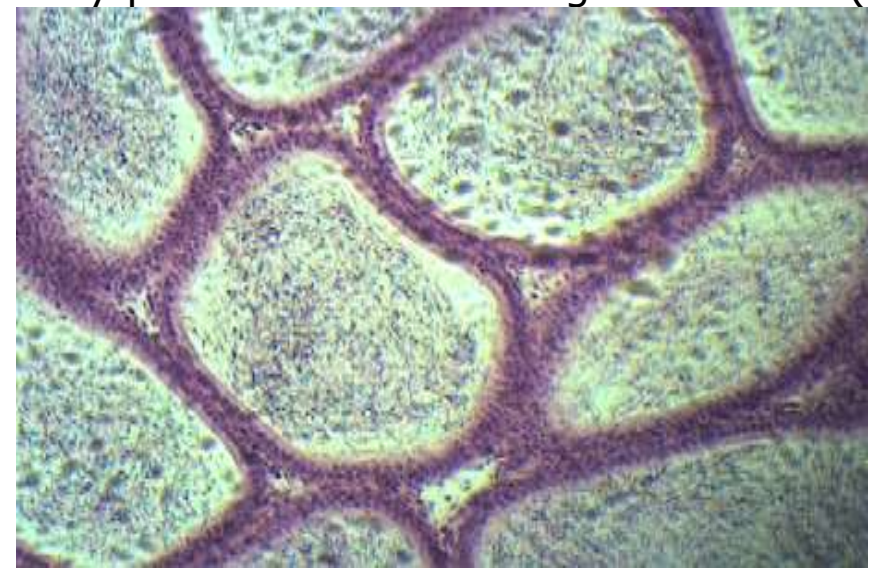

Fig. 6. Seminal vesicles of a rat after injection of ferule. The walls are lined with low prismatic epithelium with signs of destructive changes. Stained with hematoxylin and eosin. Obj. 20, about 10

Therefore, the injection of ferule in experimental animals contributes to the reduction of the secretory department and stroma of the gland, changes in the mucosa and other membranes of the seminal vesicles, some morphological shift of the spermatogenic epithelium and interstitial tissue of the testes.

\section{Conclusions}

1. The Drug ferule according to the parameters of acute toxicity in the per os method of use belongs to the category of practically non-toxic substances of the $\mathrm{V}$-class.

2. When re-used, it does not cumulate in the body of experimental animals. 
3. Long-term injection of ferulen was well experiencied by experimental animals. Biochemical parameters indicated that under the influence of ferulen, depending on the doze of injection, the content of urea, B-lipoproteins, cholestrol, and lipids are decreased. The weight and the destructive changes of androgen-dependent organs significantly reduced.

4. Ferule was successfully tested on a clinical trial on 150 patients diagnosed with various stages of prostate cancer.

Currently, the drug under the brand name "простаник" ("prostanic») is at the stage of registration.

\section{References}

1. R. M. Khalilov, A. U. Mamatkhanov, L. D. Kotenko, Technology of obtaining the estrogenic drug Ferule from the roots of a thin-cut ferule (Chemical - pharmaceutical journal. Moscow 2009. volume 43, № 10. pp. 40-43.

2. Kotenko L. D., Khalilov R. M., Mamatkhanov A. U. Methods of qualitative and quantitative analysis of the sum of esters from the roots of Ferula tenuisecta. Chemistry of plant raw materials. Barnaul, 2009, № 1. pp. 89-92.

3. Khalilov R. M. "Development of technology for the production of substances based on flavanoids and terpenoids from plant species of the Fabaceae and Apiaceae families". Author's abstract of the dissertation of the Doctor of Science (DSc). Tashkent, 2018.

4. Saidkhodzhaev A. I., Nikonov G. N., "Structure of Ferule", Chemistry of natural compounds, 1974 , no. 1 , pp. 166-170.

5. Sagitdinov G. V., Saidkhodzhaev A. I., Malikov V. M. "Structure of uniferon and uniferidine" Chemistry of natural compounds, 1978, no. 6, pp. 804-810.

6. A. G. Kurmukov, H. S. Akhmedkhodzhayeva. Estrogenic healing drugs from plants of the genus Ferula. Tashkent, Ibn Sino Publishing house, 1994.

7. A. U. Mamatkhanov, S. S. Nasrullaev, M. A. Mamatkhanova. Estrogenic activity of the sum of terpenoids from Ferula tenuisecta-panoferol and its effect on the productivity of laying hens (materials of Rep. Scientific and practical conferences. "Actual problems of biology and its teaching". -ASDCF Tashkent, 2009. - p. 436-437.

8. H. R. Akhmedkhodjaeva, V. F. Tuhtasheva, J. Rejepov, F. N. Jahangirov, A. A. Azamatov, "Preclinical study of acute toxicity and estrogenic activity of Feralen" journal of Infection, immunity and pharmacology Tashkent-2018. No. 1.

9. V. F. Tuhtasheva, J. Rejepov, F. N. Jahangirov, A. A. Azamatov, M. A. Amonov, "Study on the antiandrogen activity of ferule in the experiment European applied sciences 2018. No. 1. p.30-32.

10. Belenky M. L. Elements of a quantitative assessment of pharmacological effect. L.,1963. 